\title{
Toxoplasma gondii Infection in Marine Animal Species, as a Potential Source of Food Contamination: A Systematic Review and Meta-Analysis
}

\author{
Ehsan Ahmadpour ${ }^{1,2} \cdot$ Mohamad Taghi Rahimi $^{3} \cdot$ Altin Ghojoghi $^{4} \cdot$ Fatemeh Rezaei $^{5} \cdot$ Kareem Hatam-Nahavandi $^{6}$. \\ Sónia M. R. Oliveira ${ }^{7,8} \cdot$ Maria de Lourdes Pereira ${ }^{7,9} \cdot$ Hamidreza Majidiani $^{10} \cdot$ Abolghasem Siyadatpanah $^{11}$. \\ Samira Elhamirad ${ }^{12} \cdot$ Wei Cong $^{13} \cdot$ Abdol Sattar Pagheh $^{12}$ (D)
}

Received: 30 August 2021 / Accepted: 9 December 2021 / Published online: 17 January 2022

(c) The Author(s) under exclusive licence to Witold Stefański Institute of Parasitology, Polish Academy of Sciences 2022

\begin{abstract}
Purpose Many marine animals are infected and susceptible to toxoplasmosis, which is considered as a potential transmission source of Toxoplasma gondii to other hosts, especially humans. The current systematic review and meta-analysis aimed to determine the prevalence of $T$. gondii infection among sea animal species worldwide and highlight the existing gaps.

Methods Data collection was systematically done through searching databases, including PubMed, Science Direct, Google Scholar, Scopus, and Web of Science from 1997 to July 2020.

Results Our search strategy resulted in the retrieval of 55 eligible studies reporting the prevalence of marine $T$. gondii infection. The highest prevalence belonged to mustelids (sea otter) with 54.8\% (95\% CI 34.21-74.57) and cetaceans (whale, dolphin, and porpoise) with 30.92\% (95\% CI 17.85-45.76). The microscopic agglutination test (MAT) with 41 records and indirect immunofluorescence assay (IFA) with 30 records were the most applied diagnostic techniques for T. gondii detection in marine species.

Conclusions Our results indicated the geographic distribution and spectrum of infected marine species with T. gondii in different parts of the world. The spread of $T$. gondii among marine animals can affect the health of humans and other animals; in addition, it is possible that marine mammals act as sentinels of environmental contamination, especially the parasites by consuming water or prey species.
\end{abstract}

Abdol Sattar Pagheh

satar2011@gmail.com; pagheh.as@bums.ac.ir

1 Infectious and Tropical Diseases Research Center, Tabriz University of Medical Sciences, Tabriz, Iran

2 Department of Parasitology and Mycology, Faculty of Medicine, Tabriz University of Medical Sciences, Tabriz, Iran

3 School of Medicine, Shahroud University of Medical Sciences, Shahroud, Iran

4 Department of Fisheries, Gorgan University of Agricultural Sciences and Natural Resources, Gorgān, Iran

5 Islamic Azad University of Chalus Branch, Chalus, Iran

6 School of Medicine, Iranshahr University of Medical Sciences, Iranshahr, Iran
7 CICECO-Aveiro Institute of Materials, University of Aveiro, Aveiro, Portugal

8 Hunter Medical Research Institute (HMRI), New Lambton Heights, NSW, Australia

9 Department of Medical Sciences, University of Aveiro, Aveiro, Portugal

10 Department of Parasitology, Faculty of Medical Sciences, Tarbiat Modares University, Tehran, Iran

11 Ferdows Paramedical School, Birjand University of Medical Sciences, Birjand, Iran

12 Infectious Diseases Research Center, Birjand University of Medical Sciences, PO Box 9717853577, Birjand, Iran

13 Marine College, Shandong University, Weihai, China 


\section{Graphical Abstract}

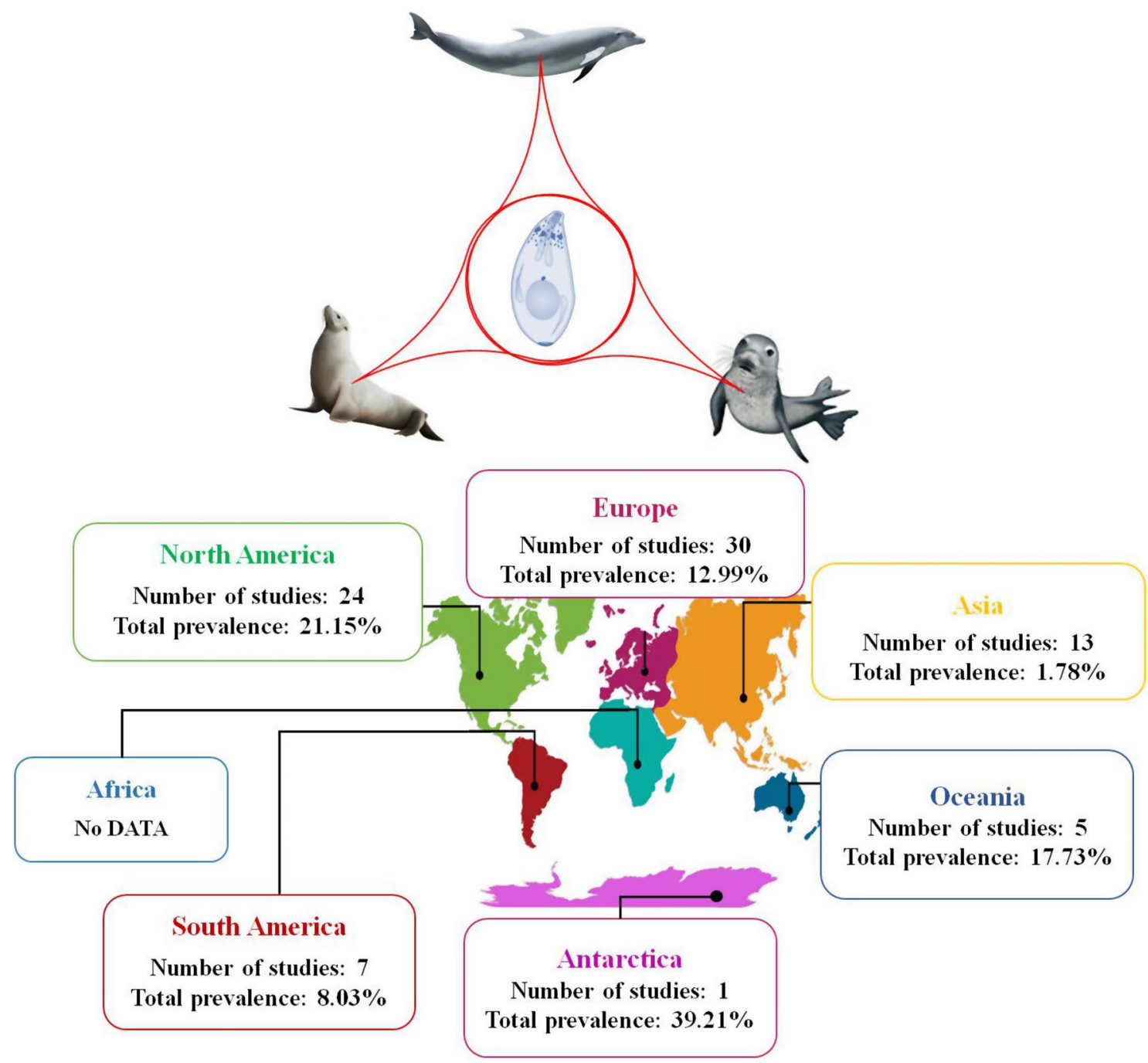

Keywords Toxoplasma gondii $\cdot$ Toxoplasmosis $\cdot$ Marine animals $\cdot$ Systematic review $\cdot$ Meta-analysis

\section{Introduction}

Marine species constitute a very diverse group of animals with global distribution, mostly along coastal regions or habitat [1]. The human population density in coastal areas greatly increased during the recent decades and zoonotic pathogens can be transmitted to humans directly or indirectly from marine animals [2]. Thus, the health of marine mammals can substantially influence human's well-being. Toxoplasmosis, caused by the intracellular protozoan Toxoplasma gondii, is a zoonotic infection with felids as definitive hosts, and a wide range of homoeothermic vertebrates as intermediate hosts [3, 4]. Pregnant women and immunocompromised patients are at a higher risk for developing the clinical disease with harsh outcomes, including congenital toxoplasmosis (hydrocephalus, chorioretinitis, and cerebral calcifications) and lifethreatening encephalitis [5-7]. Understanding $T$. gondii transmission routes in wild, free-ranging marine mammals is problematic. There are three possible routes by which marine animals could become infected with $T$. gondii, including: ingestion of oocysts, ingestion of bradyzoites in tissue cysts of other intermediate hosts or vertically. Oocysts are shed via cat feces into the environment, which can readily infect several animal species $[8,9]$. Small $T$. gondii oocysts show remarkable resistance to common disinfectants and remain alive in moist surroundings, even when exposed to a vast range of salinity and temperature 
conditions. This environmental tolerance leads to in fast and extensive dispersal of infection, particularly following heavy rain falls. The runoff originated from rainfalls alongside wastewater outfalls being likely contaminated with stray/feral cat fecal material make a huge depot of infective oocysts, which are usually discharged into a water body, i.e., sea and ocean, posing potential risk of $T$. gondii infection in those species dwelling in marine habitats [10]. In another way, marine animals acquired infection through ingestion of $T$. gondii protozoal cyst containing numerous bradyzoites. In areas where definitive hosts are rare and the viability of oocysts are likely limited due to freezing conditions, such as the Canadian Arctic, this could explain how animals are exposed to T. gondii. A number of investigators have pointed out that oocysts and bradyzoites of $T$. gondii are concentrated by oysters, clams and mussels during filter-feeding activity. It is noteworthy that the role of vertical transmission of toxoplasmosis in marine animals is unknown [9]. These are highly promising findings, but the precise mode of transmission is still open to question. Experimentally, oocyst sporulation occurs in seawater, remaining infective for animals for 6-24 months, depending on the temperature [11, 12].

During the last decades, a number of studies have reported T. gondii infection in marine animals, such as cetaceans, pinnipeds, sirenians, and sea otters (Enhydra lutris) [13-16]. Disseminated clinical disease has also been documented in adult or sometimes neonate marine mammals from Europe, USA, and Australia [17-19], with some degree of morbidity observed, for example, in the sea otters $[13,20,21]$ and in the Pacific harbor seal (Phoca vitulina richardsi) [22, 23]. Furthermore, it seems that some species have been threatened and endangered in part due to toxoplasmosis [3, 24].

The increasing amount of anthropogenic toxicants discharged into the marine environment, as well as morbillivirus infection, can suppress the immunity of marine mammals and give rise to clinical toxoplasmosis susceptibility, yet in others cases, no links to concurrent disease have been identified [25, 26]. Since $T$. gondii is a pronounced hallmark of aquatic pollution and marine species are superb sentinel animals in marine life [27-29], it would be beneficial to assess the status of $T$. gondii infection in these animals. Thus, the current systematic review and meta-analysis aimed to investigate the prevalence of $T$. gondii infection among marine animal species worldwide and highlight the existing gaps.

\section{Materials and Methods}

\section{Search Strategy}

This study was prepared and performed in accordance with the PRISMA (Preferred Reporting Items for Systematic reviews and Meta-Analyses) statement [30]. Data were systematically searched and collected from English language databases including PubMed, Science Direct, Google Scholar, Scopus, ISI Web of Science, published from inception to 1 January, 2020 by two investigators (FR and ASP).

The search process was performed using the following keywords and medical subject headings (MeSH) terms: "Toxoplasma gondii", "Toxoplasmosis", "T. gondii" in combination with "fishes", "marine mammals"; "oyster", "Shellfish", "mussels", "dolphin”, "shark", “crab”, "seal”, "sea lion", "whale", "sea otter", "porpoise", "shrimp", "Manatees", "Walruses", "Eel", "crayfish", and "turtle". To avoid missing of any paper, the reference list of relevant papers was screened manually.

\section{Study Selection}

For the first screening, the two independent authors (ASP and FR) surveyed the title and the abstract of all papers returned from the search process. To ensure the eligibility for inclusion to the systematic review, full texts of papers were also reviewed by investigators (ASP and FR), and any disagreement on articles selected was resolved.

\section{Quality Evaluation}

Selected articles were assessed according to a checklist used in previous studies [31]. This checklist was based on contents of the strengthening the reporting of observational studies in epidemiology (STROBE) checklist containing questions about various methodological aspects such as type of study, sample size, study population, data collection approaches and tools, sampling methods, variables estimation status, methodology, research objectives and demonstration of results according to the objectives [32]. For each question, a score was attributed and articles with a score of at least seven were selected articles. In addition, any disagreements with selected papers were reviewed by another author.

\section{Selection Criteria and Data Extraction}

Papers were included in the meta-analysis with the following criteria: (1) original articles; (2) studies in English language; (2) articles available in full-text; (3) studies that evaluated the prevalence of $T$. gondii infection in marine animals. On the other hand, the exclusion criteria entailed: case reports, review articles, letter to the editor, unclear or not technically acceptable diagnostic criteria, insufficient information, congress articles, as well as those with unavailable full-text. After reviewing all articles, papers without sufficient information and that did not obtain the minimum quality score were excluded. 


\section{Meta-Analysis}

In this study, a forest plot was used to visualize the summarized results and heterogeneity among the included studies. The size of every square indicated the weight of every study as well as crossed lines presented confidence intervals, CI. To assess heterogeneity index, Cochran's $Q$ test and $I^{2}$ statistics were applied. Additionally, a funnel plot was designed to determine the small study effects and their publication bias, based on Egger's regression test. The meta-analysis was conducted using Stats Direct statistical software (http://www.statsdirect.com). A $P$ value less than 0.05 was considered statistically significant. Additional meta-analysis was performed based on the type of host, location and diagnostic method.

\section{Results}

A total of 5175 papers were analyzed by exploration of PubMed, Science Direct, Scopus, Google Scholar, and ISI Web of Science databases, and finally 55 records were found to be eligible for the current systematic review and metaanalysis. The searching and study selection procedures are illustrated in Fig. 1. Based on Continent, the highest number of investigations was from Europe (30 studies) with a total prevalence of $12.99 \%$, and marine mustelids were the most infected group with $53.12 \%$. It is also worth noting that 24 studies from North America were included in this systematic review, indicating a total prevalence of $21.15 \%$, and an exceptionally high infection rate among cetaceans was observed in this continent (80.85\%). In Asian countries, a low prevalence rate of $1.78 \%$ was reported and the pinnipeds were the most infected group with 29.2\%. In South America,

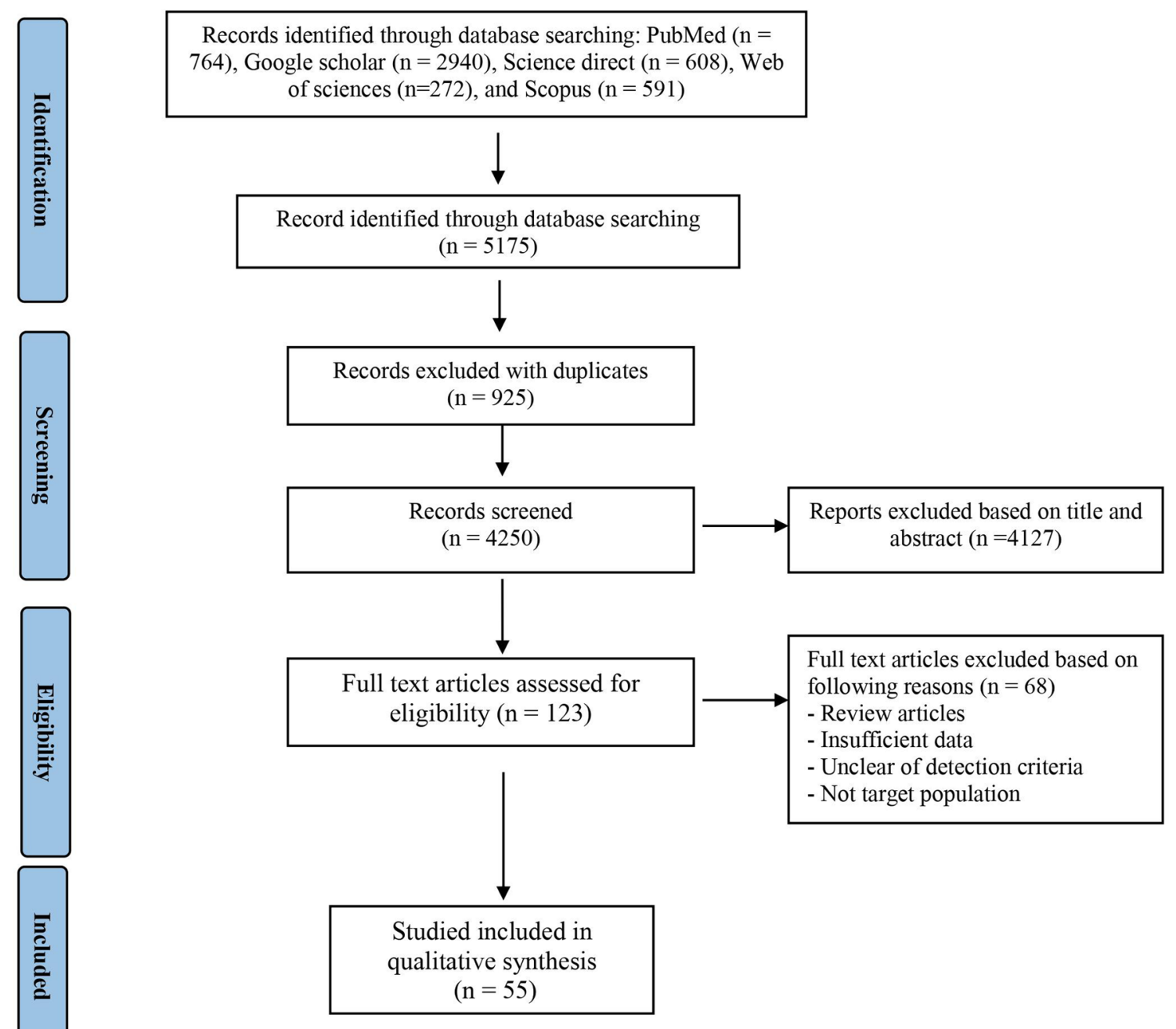

Fig. 1 Flowchart describing the study design process 
a pooled prevalence of $8.03 \%$ was reported with the highest infection in cetaceans (30.35\%). In Oceania, the pooled prevalence was $17.73 \%$ and cetaceans were the most infected species $(26.12 \%)$. In addition, the pooled prevalence rate in Antarctica was $39.21 \%$ in pinnipeds. On the other hand, no reports were found for the North Pole and the African continent (Fig. 2).

According to Table 1, T. gondii infection was detected in dolphins (45 entries), whales (29 entries), seals (31 entries), sea lions ( 5 entries), sea otters (10 entries), porpoise (3 entries), oysters/mussels/shellfish (11 entries), fishes (4 entries), shrimp ( 2 entries), manatees ( 2 entries), walruses, eel and crayfish (single record for each) using serological and/or molecular techniques. Most reports were from the USA and Brazil with 24 records for each country, followed by Scotland (15 records), Italy (13 records), China (10 records), Spain (9 records), Canada and United Kingdom (8 records for each), Mexico (5 records), Norway and Russia (4 records for each), New Zealand (3 records), Japan (2 records) as well as single records from Iran, Turkey, Portugal, Netherlands, Peru, Australia and Solomon Islands. Altogether, eight serological methods were employed to determine T. gondii infection among marine animals. These include the modified agglutination test (MAT) as the most used technique (41 records), followed by immunofluorescence antibody test (IFA) (30 records) and immunohistochemistry (IHC) (21 records). Moreover, 17 entries used conventional polymerase chain reaction (PCR), being this the most used molecular technique, followed by nested-PCR (7 records) and quantitative PCR (qPCR) (4 records). Subgroup analysis (Table 2) showed that most studies were focused on cetaceans (whale, dolphin and porpoise) (36 studies), whereas the highest prevalence rate of $T$. gondii infection belonged to marine mustelids (sea otter, 10 studies) with 54.8\% (95\% CI 34.21-74.57\%). Pooled proportion of $T$. gondii infection in dolphin species was of 51.07\%. According to Egger's test, the prevalence rates in cetaceans $(P$ value $=0.0489)$ and pinnipeds $(P$ value $=0.0004)$ were statistically significant.

\section{Discussion}

The present systematic review and meta-analysis aimed to determine the prevalence rate of $T$. gondii infection worldwide. The obtained data were categorized based on the species of marine animals, continents, and diagnostic techniques. Among marine animals, the prevalence of $T$. gondii infection was higher in the population of sea otters (54.8\%). In a study, Miller et al. [33] suggested that coastal freshwater runoff is a risk factor for toxoplasmosis in southern sea otters

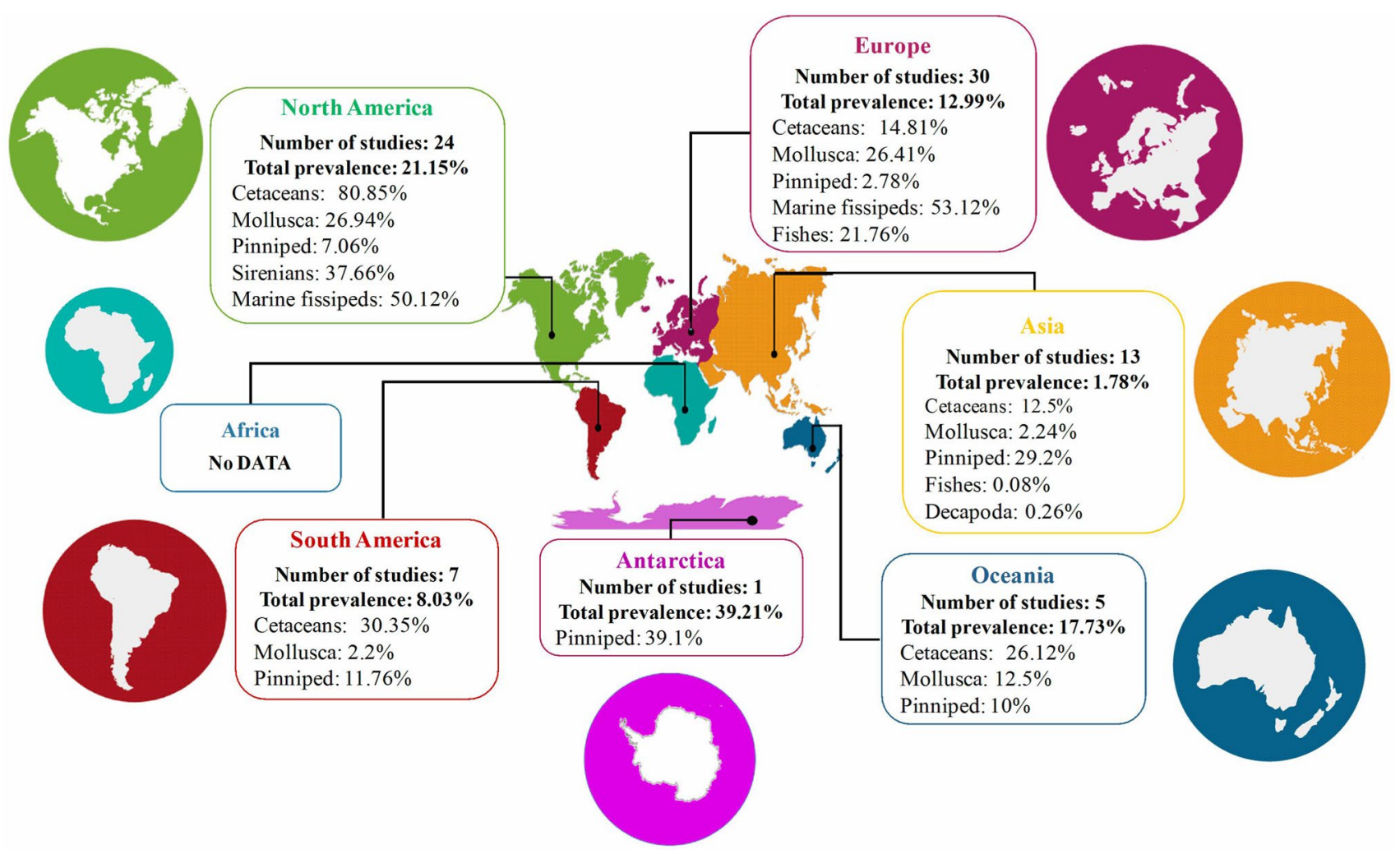

Fig. 2 Pooled prevalence of $T$. gondii in marine animal species in different continents 
Table 1 Detection of Toxoplasma gondii in marine animals (sorted by scientific name and publication date)

\begin{tabular}{|c|c|c|c|c|c|c|}
\hline Species & Location & Continent & Test & Sample size & Positive (\%) & References \\
\hline \multicolumn{7}{|l|}{ Dolphin } \\
\hline Tursiops truncatus & USA & North America & MAT & 141 & $138(97.9)$ & Dubey et al. [17] \\
\hline Sousa chinensis & Australia & Australia & $\mathrm{IHC}$ & 4 & $4(100)$ & Bowater et al. [47] \\
\hline Stenella coeruleoalba & Spain & Europe & MAT & 36 & $4(11.1)$ & Cabezón et al [48] \\
\hline Delphinus delphis & Spain & Europe & MAT & 4 & $2(50)$ & Cabezón et al. [48] \\
\hline Tursiops truncatus & Spain & Europe & MAT & 7 & $4(57.1)$ & Cabezón et al. [48] \\
\hline Phocoena phocoena & Spain & Europe & MAT & 1 & $1(100)$ & Cabezón et al. [48] \\
\hline Grampus griseus & Spain & Europe & MAT & 9 & 0 & Cabezón et al. [48] \\
\hline Tursiops aduncus & Solomon Islands & Oceania & Immunoblotting & 58 & $8(13.8)$ & Omata et al. [49] \\
\hline $\begin{array}{l}\text { Tursiops truncatus } \\
\text { ponticus }\end{array}$ & Russia & Europe & ELISA & 59 & $27(45.7)$ & Alekseev et al. [50] \\
\hline Tursiops truncatus & USA & North America & MAT & 52 & $27(51.9)$ & Dubey et al. [44] \\
\hline $\begin{array}{l}\text { Tursiops truncatus } \\
\text { ponticus }\end{array}$ & Russia & Europe & ELISA & 74 & $39(52.7)$ & Alekseev et al. [51] \\
\hline Tursiops truncatus & USA & North America & MAT & 7 & $7(100)$ & Dubey et al. [18] \\
\hline Delphinus delphis & United Kingdom & Europe & Sabin Feldman & 21 & $6(28.5)$ & Forman et al. [52] \\
\hline Grampus griseus & United Kingdom & Europe & Sabin Feldman & 1 & 0 & Forman et al. [52] \\
\hline Lagenorhynchus acutus & United Kingdom & Europe & Sabin Feldman & 1 & 0 & Forman et al. [52] \\
\hline Tursiops truncatus & United Kingdom & Europe & Sabin Feldman & 1 & 0 & Forman et al. [52] \\
\hline Stenella coeruleoalba & United Kingdom & Europe & Sabin Feldman & 5 & 0 & Forman et al. [52] \\
\hline Stenella coeruleoalba & Italy & Europe & IFA & 8 & $4(50)$ & Di Guardo et al. [53] \\
\hline Tursiops truncates & Italy & Europe & Nested-PCR and MAT & 8 & $7(87.5)$ & Pretti et al. [54] \\
\hline Stenella coeruleoalba & Italy & Europe & Nested-PCR and MAT & 6 & $6(100)$ & Pretti et al. [54] \\
\hline Inia geoffrensis & Brazil & South America & MAT & 95 & $82(86.3)$ & Santos et al. [55] \\
\hline $\begin{array}{l}\text { Tursiops truncatus } \\
\text { truncatus }\end{array}$ & Mexico & North America & MAT & 63 & $55(87.3)$ & $\begin{array}{l}\text { Alvarado-Esquivel et al. } \\
\text { [56] }\end{array}$ \\
\hline $\begin{array}{l}\text { Tursiops truncatus } \\
\text { gillii }\end{array}$ & Mexico & North America & MAT & 3 & $3(100)$ & $\begin{array}{l}\text { Alvarado-Esquivel et al. } \\
\text { [56] }\end{array}$ \\
\hline $\begin{array}{l}\text { Cephalorhynchys } \\
\text { hectori }\end{array}$ & New Zealand & Oceania & PCR & 49 & $17(34.7)$ & Roe et al. [57] \\
\hline Tursiops truncatus & Spain & Europe & IFA & 24 & $2(8.3)$ & $\begin{array}{l}\text { Bernal-Guadarrama et } \\
\text { al. }[58]\end{array}$ \\
\hline Stenella coeruleoalba & Italy & Europe & IFA & 18 & $8(44.4)$ & Profeta et al. [59] \\
\hline Tursiops truncatus & Italy & Europe & IFA & 3 & $2(66.6)$ & Profeta et al. [59] \\
\hline Grampus griseus & Scotland & Europe & IFA & 7 & $2(28.5)$ & et al. [26] \\
\hline Delphinus delphis & Scotland & Europe & IFA & 13 & $2(15.4)$ & van de Velde et al. [26] \\
\hline Stenella coeruleoalba & Scotland & Europe & IFA & 9 & 0 & van de Velde et al. [26] \\
\hline $\begin{array}{l}\text { Lagenorhynchus albi- } \\
\text { rostris }\end{array}$ & Scotland & Europe & IFA & 6 & $1(16.6)$ & van de Velde et al. [26] \\
\hline Stenella coeruleoalba & Italy & Europe & PCR & 10 & $6(60)$ & Pintore et al. [60] \\
\hline Tursiops truncatus & Italy & Europe & PCR & 1 & $1(100)$ & Pintore et al. [60] \\
\hline Steno bredanensis & Brazil & South America & $\mathrm{IHC}$ & 3 & 0 & Costa-Silva et al. [61] \\
\hline Lagenodelphis hosei & Brazil & South America & IHC & 2 & 0 & Costa-Silva et al. [61] \\
\hline Sotalia guianensis & Brazil & South America & $\mathrm{IHC}$ & 27 & $1(3.7)$ & Costa-Silva et al. [61] \\
\hline Tursiops truncatus & Brazil & South America & $\mathrm{IHC}$ & 4 & $1(25)$ & Costa-Silva et al. [61] \\
\hline Pontoporia blainvillei & Brazil & South America & $\mathrm{IHC}$ & 102 & 0 & Costa-Silva et al. [61] \\
\hline Stenella frontalis & Brazil & South America & $\mathrm{IHC}$ & 6 & 0 & Costa-Silva et al. [61] \\
\hline Stenella longirostris & Brazil & South America & IHC & 5 & 0 & Costa-Silva et al. [61] \\
\hline Stenella clymene & Brazil & South America & IHC & 6 & 0 & Costa-Silva et al. [61] \\
\hline Stenella coeruleoalba & Brazil & South America & IHC & 2 & 0 & Costa-Silva et al. [61] \\
\hline Delphinus delphis & Brazil & South America & IHC & 1 & 0 & Costa-Silva et al. [61] \\
\hline
\end{tabular}


Table 1 (continued)

\begin{tabular}{|c|c|c|c|c|c|c|}
\hline Species & Location & Continent & Test & Sample size & Positive (\%) & References \\
\hline Delphinus delphis & Brazil & South America & IHC & 1 & 0 & Costa-Silva et al. [61] \\
\hline Inia geoffrensis & Brazil & South America & IHC & 1 & 0 & Costa-Silva et al. [61] \\
\hline \multicolumn{7}{|l|}{ Whale } \\
\hline $\begin{array}{l}\text { Balaenoptera acuto- } \\
\text { rostrata }\end{array}$ & Norway & Europe & MAT & 202 & 0 & Oksanen et al. [62] \\
\hline Delphinapterus leucas & USA & North America & MAT & 3 & 0 & Dubey et al. [17] \\
\hline Globicephala melas & Spain & Europe & MAT & 1 & 0 & Cabezón et al. [48] \\
\hline Orcinus orca & Japan & Asia & PCR & 8 & $1(12.5)$ & Omata et al. [49] \\
\hline Delphinapterus leucas & Russia & Europe & ELISA & 147 & $7(4.7)$ & Alekseev et al. [51] \\
\hline $\begin{array}{l}\text { Megaptera novaean- } \\
\text { gliae }\end{array}$ & United Kingdom & Europe & Sabin Feldman & 1 & $1(100)$ & Forman et al. [52] \\
\hline Ziphius cavirostris & United Kingdom & Europe & Sabin Feldman & 1 & 0 & Forman et al. [52] \\
\hline $\begin{array}{l}\text { Physeter macrocepha- } \\
\quad \text { lus }\end{array}$ & Portugal & Europe & $\mathrm{qPCR}$ & 5 & 0 & Hermosilla et al. [63] \\
\hline Balaenoptera physalus & Italy & Europe & IFA & 1 & 0 & van de Velde et al. [26] \\
\hline Globicephala melas & Italy & Europe & IFA & 1 & 0 & van de Velde et al. [26] \\
\hline Balaenoptera physalus & Scotland & Europe & IFA & 1 & 0 & van de Velde et al. [26] \\
\hline Orcinus orca & Scotland & Europe & IFA & 3 & 0 & van de Velde et al. [26] \\
\hline Globicephala melas & Scotland & Europe & IFA & 10 & $4(40)$ & van de Velde et al. [26] \\
\hline $\begin{array}{l}\text { Balaenoptera acuto- } \\
\text { rostrata }\end{array}$ & Scotland & Europe & IFA & 5 & 0 & van de Velde et al. [26] \\
\hline Mesoplodon bidens & Scotland & Europe & IFA & 4 & 0 & van de Velde et al. [26] \\
\hline $\begin{array}{l}\text { Physeter macrocepha- } \\
\quad \text { lus }\end{array}$ & Scotland & Europe & IFA & 2 & 0 & Alekseev et al. 2017 [64] \\
\hline Balaenoptera borealis & Scotland & Europe & IFA & 1 & 0 & Iqbal et al. [65] \\
\hline Delphinapterus leucas & Russia & Europe & ELISA & 87 & $10(11.5)$ & Profeta et al. [59] \\
\hline Delphinapterus leucas & Canada & North America & PCR & 34 & $15(44.1)$ & Profeta et al. [59] \\
\hline Globicephala melas & Italy & Europe & PCR & 1 & 0 & Pintore et al. [60] \\
\hline Kogia sima & Brazil & South America & IHC & 7 & 0 & Costa-Silva et al. [61] \\
\hline Peponocephala electra & Brazil & South America & $\mathrm{IHC}$ & 5 & 0 & Costa-Silva et al. [61] \\
\hline $\begin{array}{l}\text { Globicephala macro- } \\
\text { rhynchus }\end{array}$ & Brazil & South America & $\mathrm{IHC}$ & 3 & 0 & Costa-Silva et al. [61] \\
\hline $\begin{array}{l}\text { Physeter macrocepha- } \\
\quad \text { lus }\end{array}$ & Brazil & South America & IHC & 3 & 0 & Costa-Silva et al. [61] \\
\hline Kogia breviceps & Brazil & South America & $\mathrm{IHC}$ & 2 & 0 & Costa-Silva et al. [61] \\
\hline $\begin{array}{l}\text { Megaptera novaean- } \\
\text { gliae }\end{array}$ & Brazil & South America & IHC & 2 & 0 & Costa-Silva et al. [61] \\
\hline Orcinus orca & Brazil & South America & $\mathrm{IHC}$ & 2 & $1(50)$ & Costa-Silva et al. [61] \\
\hline Mesoplodon europaeus & Brazil & South America & IHC & 1 & 0 & Costa-Silva et al. [61] \\
\hline Balaenoptera physalus & Italy & Europe & PCR & 7 & $1(14.2)$ & Marcer et al. [66] \\
\hline \multicolumn{7}{|l|}{ Seals } \\
\hline Phoca groenlandica & Norway & Europe & MAT & 316 & 0 & Oksanen et al. [62] \\
\hline Phoca hispida & Norway & Europe & MAT & 48 & 0 & Oksanen et al. [62] \\
\hline Cystophora cristata & Norway & Europe & MAT & 78 & 0 & Oksanen et al. [62] \\
\hline Phoca vitulina & USA & North America & MAT & 380 & $29(7.6)$ & Lambourn et al. [67] \\
\hline Phoca vitulina & USA & North America & MAT & 311 & $51(16.4)$ & Dubey et al. [17] \\
\hline Phoca hispida & USA & North America & MAT & 32 & $5(15.6)$ & Dubey et al. [17] \\
\hline Erignathus barbatus & USA & North America & MAT & 8 & $4(50)$ & Dubey et al. [17] \\
\hline Phoca largha & USA & North America & MAT & 9 & $1(11.1)$ & Dubey et al. [17] \\
\hline Phoca fasciata & USA & North America & MAT & 14 & 0 & Dubey et al. [17] \\
\hline Phoca groenlandica & Canada & North America & MAT & 112 & 0 & Measures et al. [68] \\
\hline
\end{tabular}


Table 1 (continued)

\begin{tabular}{|c|c|c|c|c|c|c|}
\hline Species & Location & Continent & Test & Sample size & Positive (\%) & References \\
\hline Cystophora cristata & Canada & North America & MAT & 60 & $1(1.6)$ & Measures et al. [68] \\
\hline Halichoerus grypus & Canada & North America & MAT & 122 & $11(9)$ & Measures et al. [68] \\
\hline Phoca vitulina & Canada & North America & MAT & 34 & $3(8.8)$ & Measures et al. [68] \\
\hline $\begin{array}{l}\text { Phoca vitulina stej- } \\
\text { negeri }\end{array}$ & Japan & Asia & ELISA & 77 & $3(3.9)$ & Fujii et al. [9] \\
\hline Phoca vitulina vitulina & Spain & Europe & MAT & 56 & $3(5.3)$ & Cabezón et al. [48] \\
\hline Halichoerus grypus & Spain & Europe & MAT & 47 & $11(23.4)$ & Cabezón et al. [48] \\
\hline Pusa hispida & Canada & North America & DAT & 788 & $80(10.1)$ & Simon et al. [69] \\
\hline Erignathus barbatus & Canada & North America & DAT & 20 & $2(10)$ & Simon et al. [69] \\
\hline Phoca vitulina & Canada & North America & DAT & 9 & $2(22.2)$ & Simon et al. [69] \\
\hline $\begin{array}{l}\text { Leptonychotes wed- } \\
\text { dellii }\end{array}$ & Antarctic Peninsula & South America & DAT & 31 & $13(41.9)$ & Rengifo-Herrera et al. [70] \\
\hline Mirounga leonina & Antarctic Peninsula & South America & DAT & 13 & $10(76.9)$ & Rengifo-Herrera et al. [70] \\
\hline Lobodon carcinophaga & Antarctic Peninsula & South America & DAT & 2 & $1(50)$ & Rengifo-Herrera et al. [70] \\
\hline Arctocephalus gazella & Antarctic Peninsula & South America & DAT & 165 & $4(2.4)$ & Rengifo-Herrera et al. [70] \\
\hline Arctocephalus gazella & Antarctica & Antarctica & DAT & 21 & $12(57.1)$ & Jensen et al. [71] \\
\hline $\begin{array}{l}\text { Leptonychotes wed- } \\
\text { dellii }\end{array}$ & Antarctica & Antarctica & DAT & 33 & $17(51.5)$ & Jensen et al. [71] \\
\hline Mirounga leonina & Antarctica & Antarctica & DAT & 48 & $11(22.9)$ & Jensen et al. [71] \\
\hline Arctocephalus australis & Peru & South America & IFA & 27 & 0 & Jankowski et al. [72] \\
\hline Halichoerus grypus & Scotland & Europe & IFA & 13 & 0 & van de Velde et al. [26] \\
\hline Phoca vitulina & Scotland & Europe & IFA & 17 & $2(11.7)$ & van de Velde et al. [26] \\
\hline $\begin{array}{l}\text { Phoca vitulina rich- } \\
\text { ardsi }\end{array}$ & Alaska & North America & IFA & 34 & 0 & Bauer et al. [73] \\
\hline Pusa caspica & Iran & Asia & MAT & 36 & $30(83.3)$ & Namroodi et al. [74] \\
\hline \multicolumn{7}{|l|}{ Sea lions } \\
\hline Zalophus californianus & USA & North America & MAT & 45 & $19(42.2)$ & Dubey et al. [17] \\
\hline Otaria flavescens & Mexico & North America & MAT & 2 & 0 & $\begin{array}{l}\text { Alvarado-Esquivel et } \\
\text { al.[56] }\end{array}$ \\
\hline Zalophus californianus & Mexico & North America & MAT & 4 & $2(50)$ & $\begin{array}{l}\text { Alvarado-Esquivel et al. } \\
\text { [56] }\end{array}$ \\
\hline Zalophus californianus & USA & North America & IFA & 1630 & $46(2.8)$ & Carlson-Bremer et al. [75] \\
\hline Phocarctos hookeri & New Zealand & Oceania & ELISA & 50 & $5(10)$ & Michael et al. [76] \\
\hline \multicolumn{7}{|l|}{ Sea otters } \\
\hline Lontra canadensis & USA & North America & LAT & 103 & $46(44.6)$ & Tocidlowski et al. [77] \\
\hline Enhydra lutris nereis & USA & North America & IFA & 223 & $115(51.5)$ & Miller et al. [78] \\
\hline Enhydra lutris nereis & USA & North America & IFA & 80 & $29(36.2)$ & Miller et al. [78] \\
\hline Enhydra lutris kenyoni & USA & North America & IFA & 21 & $8(38.1)$ & Miller et al. [78] \\
\hline Enhydra lutris kenyoni & USA & North America & IFA & 65 & 0 & Miller et al. [78] \\
\hline Enhydra lutris nereis & USA & North America & Microscopic test & 35 & $15(42.8)$ & Miller et al. [79] \\
\hline Enhydra lutris & USA & North America & MAT & 145 & $107(73.7)$ & Dubey et al. [17] \\
\hline Lontra canadensis & USA & North America & IFA & 40 & $7(17.5)$ & Gaydos et al. [80] \\
\hline Lutra lutra & Scotland & Europe & IFA & 32 & $17(53.1)$ & van de Velde et al. [26] \\
\hline Enhydra lutris kenyoni & USA & North America & MAT & 70 & $65(92.8)$ & Verma et al. [81] \\
\hline \multicolumn{7}{|l|}{ Porpoise } \\
\hline Phocoena phocoena & United Kingdom & Europe & Sabin Feldman & 70 & $1(1.4)$ & Forman et al. [52] \\
\hline Phocoena phocoena & Netherlands & Europe & MAT & 31 & $4(12.9)$ & van de Velde et al. [26] \\
\hline Phocoena phocoena & Scotland & Europe & IFA & 98 & $2(2)$ & van de Velde et al. [26] \\
\hline \multicolumn{7}{|l|}{ Oysters/mussels/shellfish } \\
\hline Mytella guyanensis & Brazil & South America & Nested PCR & 300 & 0 & Esmerini et al. [82] \\
\hline
\end{tabular}


Table 1 (continued)

\begin{tabular}{|c|c|c|c|c|c|c|}
\hline Species & Location & Continent & Test & Sample size & Positive (\%) & References \\
\hline $\begin{array}{l}\text { Crassostrea rhizopho- } \\
\text { rae }\end{array}$ & Brazil & South America & Nested PCR & 300 & $10(3.3)$ & Esmerini et al. [82] \\
\hline $\begin{array}{l}\text { Mytilus galloprovin- } \\
\text { cialis }\end{array}$ & Turkey & Europe & HRM & 53 & $21(39.6)$ & Aksoy et al. [37] \\
\hline Ostreae concha & China & Asia & PCR & 398 & 0 & Zhang et al. [83] \\
\hline $\begin{array}{l}\text { Mytilus galloprovin- } \\
\text { cialis }\end{array}$ & Italy & Europe & $\mathrm{qPCR}$ & 53 & $7(13.2)$ & Marangi et al. [84] \\
\hline Crassostrea virginica & USA & North America & PCR & 230 & $4(1.7)$ & Marquis et al. [85] \\
\hline $\begin{array}{l}\text { Crassostrea rhizopho- } \\
\text { rae }\end{array}$ & Brazil & South America & PCR & 624 & $17(2.7)$ & Ribeiro et al. [86] \\
\hline Oysters & China & Asia & Nested PCR & 998 & $26(2.6)$ & Cong et al. [87] \\
\hline Perna canaliculus & New Zealand & Oceania & Nested PCR & 104 & $13(12.5)$ & Coupe et al. [88] \\
\hline Mytilus edulis & China & Asia & Nested PCR & 2215 & $55(2.4)$ & Cong et al. [89] \\
\hline Crassostrea virginica & USA & North America & $\mathrm{qPCR}$ & 1440 & $446(30.9)$ & Marquis et al. [90] \\
\hline \multicolumn{7}{|l|}{ Fishes } \\
\hline Carassius auratus & China & Asia & PCR & 309 & 0 & Zhang et al. [83] \\
\hline Сурrinus carpio & China & Asia & PCR & 309 & 0 & Zhang et al. [83] \\
\hline $\begin{array}{l}\text { Hypophthalmichthys } \\
\text { molitrix }\end{array}$ & China & Asia & PCR & 456 & $1(0.2)$ & Zhang et al. [83] \\
\hline Fishes & Italy & Europe & $\mathrm{qPCR}$ & 147 & $32(21.7)$ & Marino et al. [91] \\
\hline \multicolumn{7}{|l|}{ Shrimp } \\
\hline $\begin{array}{l}\text { Penaeus monodon } \\
\text { Fabricius }\end{array}$ & China & Asia & PCR & 426 & 0 & Zhang et al. [83] \\
\hline $\begin{array}{l}\text { Macrobrachium nip- } \\
\text { ponense }\end{array}$ & China & Asia & PCR & 813 & $1(0.1)$ & Zhang et al. [83] \\
\hline \multicolumn{7}{|l|}{ Manatees } \\
\hline Trichechus manatus & Mexico & North America & MAT & 3 & 0 & $\begin{array}{l}\text { Alvarado-Esquivel et al. } \\
\text { [56] }\end{array}$ \\
\hline Trichechus inunguis & & & MAT & 74 & $29(39.1)$ & Mathews et al. [15] \\
\hline \multicolumn{7}{|l|}{ Walruses } \\
\hline Odobenus rosmarus & USA & North America & MAT & 53 & $3(5.6)$ & Dubey et al. [17] \\
\hline \multicolumn{7}{|l|}{ Eel } \\
\hline Monopterus albus & China & Asia & PCR & 98 & 0 & Zhang et al. [83] \\
\hline \multicolumn{7}{|l|}{ Crayfish } \\
\hline Procambarus clarkii & China & Asia & PCR & 618 & $4(0.64)$ & Zhang et al. [83] \\
\hline
\end{tabular}

$I H C$ immunohistochemistry, IFA immunofluorescence antibody test, DAT direct agglutination test, $L A T$ latex agglutination test, $H R M$ real time $\mathrm{PCR} /$ high-resolution melting analysis, IHAT indirect hemagglutination test

(Enhydra lutris nereis) in southern California. Furthermore, it has been shown that exposure to $T$. gondii among sea otters was highly influenced by individual animal prey choice and habitat use [34]. Toxoplasmosis had considerable morbidity and mortality rates in the sea otter [35]. T. gondii encephalitis in sea otters causes high mortality rate and is responsible for slow population recovery, particularly for the endangered Southern sea otter [27]. In addition, cetaceans were the most infected animals in North America, South America, and Oceania.
Modified agglutination test (MAT) was the most applied diagnostic assay for $T$. gondii detection in marine animals. This technique is widely employed in research of toxoplasmosis in humans and in all species of animals because it is considered as a rapid and simple approach without the requirement for special facilities [36]. Molecular methods, particularly polymerase chain reaction (PCR) and nested PCR, were used in marine animals usually as a food source for humans like fishes, shrimp, oysters, and crayfish, amongst others. Some studies indicate that consumption of contaminated raw shellfish and mussels can be considered a 


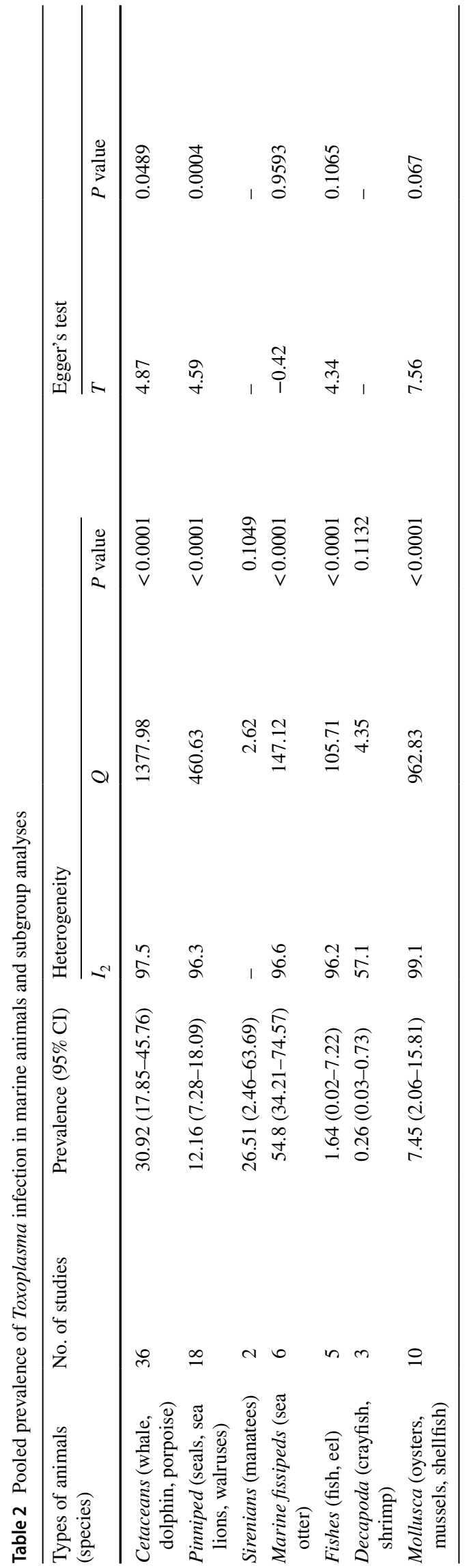

significant health danger due to their ability to infect a wide variety of hosts such as other marine animals and humans. However, they are particularly at risk for $T$. gondii infection, and therefore, they can be considered a bioindicator for monitoring waterborne pathogens [37, 38]. The high prevalence rate of $T$. gondii in the examined marine species may indicate that the nearby terrestrial environment in the studied area was heavily contaminated by $T$. gondii, and consequently, contamination was transferred to the aquatic environment. Furthermore, marine hosts may associate with T. gondii infection as paratenic hosts in some area [39]. Hence, contamination of marine animal species is an important bioindicator for contamination of aquatic environments.

Each cat, as final host for T. gondii, shed over 3-810 million oocysts. The sporulation of the oocysts takes $1-5$ days, and they can remain infective in the soil for up to 18 months [40]. Furthermore, experiments showed that oocysts of $T$. gondii can sporulate in sea water and survive at $4{ }^{\circ} \mathrm{C}$ for 24 months and then infect mice [12]. One important factor in infected hosts is the strain of the parasite, which plays a major role in the toxoplasmosis prognosis. So far, the genotypes $T$. gondii were classified as classical types I, II, III, mix/recombinant atypical, and African lineages [41]. Comparison between $T$. gondii genotypes from the marine and terrestrial environments would help clarify routs and mechanisms of land-sea transmission. Type I strains, which are highly virulent and pathogenic, can lead to acquired ocular toxoplasmosis in individuals with disseminated congenital form of $T$. gondii [42, 43]. Aksoy et al. [37] reported T. gondii type 1 infection in Mytilus galloprovincialis (Mediterranean mussel), one of the most consumed shellfish in Turkey. The authors suggested that these types of contaminated seafood may be involved in the transmission of the parasite to humans and other hosts. Type II T. gondii strains are the vast majority of human infections and have a worldwide distribution. Type II strains are causative agents for numerous asymptomatic toxoplasmosis cases in Europe, it can be pathogenic for two important categories of subjects, namely immature fetuses and immunocompromised individuals [43]. On the basis of a previous study, Dubey et al. [44] showed Type II T. gondii from a striped dolphin (Stenella coeruleo$a l b a$ ) in Costa Rica. It is noteworthy that Type III T. gondii in mice are classified as avirulent strain. Study carried out by Hancock et al. [45] showed the first report of type III T. gondii in a Hawaiian monk seal. This genotype was determined to be restriction fragment length polymorphisms (RFLP) of the SAG2 gene. On the other hand, it has previously been shown that Type X strains of $T$. gondii are virulent for southern sea otters from coastal California [27]. Additionally, one interesting study has demonstrated Type X strains of $T$. gondii in canids, coastal-dwelling felids, nearshore-dwelling sea otters, and marine bivalve. It is assumed that contaminated runoff to feline faecal rapidly reaches sea from lands, and 
otters could be infected with $T$. gondii via the consumption of filter-feeding marine invertebrates [46].

The prevalence rate of marine $T$. gondii infection in various regions of the world was very different, and ranged from 0 to $100 \%$. These differences may originate from different types of marine animals, sample sizes, and diagnostic approaches in the reviewed studies. Regarding continents, North America showed the highest $T$. gondii infection in marine animals that may suggest the level of fecal contamination of the soil and water reservoirs. Our analysis also showed that there is either no available data (Africa) or very limited literature (Antarctica, Oceania, and South America) on the prevalence of $T$. gondii infection in significant parts of the globe. Therefore, it is essential to conduct more studies to determine the putative role of $T$. gondii on marine species. The main limitation expressed in the included studies regarding prevalence of $T$. gondii infection in marine animal species was related to the use of different diagnostic methods with varying sensitivity and specificity due to their great impact on the results. The use of an accurate and reliable technique can help to correctly interpret the results of $T$. gondii prevalence in marine species in different parts of the world.

\section{Conclusion}

The results of current study indicated that the global prevalence rate of $T$. gondii infection was high in marine animals. It is well demonstrated that $T$. gondii parasite has a very successful adaptation in aquatic environments. Despite the worldwide range and broad marine animals host record of $T$. gondii infection, there was no evidence regarding toxoplasmosis in these animals in most parts of the world. Therefore, it is necessary to develop surveillance for detection of $T$. gondii in aquatic animals in different regions with appropriate molecular and serological techniques. It is also important to know the ecology of this parasite in aquatic environment to design appropriate strategies for monitoring, controlling, and prevention of the transmission of toxoplasmosis to humans or other hosts.

Supplementary Information The online version contains supplementary material available at https://doi.org/10.1007/s11686-021-00507-z.

Acknowledgements Maria de Lourdes Pereira acknowledge project CICECO-Aveiro Institute of Materials, UIDB/50011/2020 and UIDP/50011/2020.

Author Contributions Conceptualization, ASP and EA; methodology, ASP, FR. and MTR; formal analysis, EA, AG and SMO; investigation, HM, AS, and MLP; data curation, EA and MLP; writing original draft preparation, ASP, MTR, HM; writing-review and editing, EA, MLP, and ASP; all authors have read and agreed to the published version of the manuscript.

\section{Declarations}

Conflict of Interest The authors declare that there is no conflict of interest regarding the publication of this article.

Availability of Data and Material Data supporting the conclusions of this article are included within the article.

\section{References}

1. Mikaelian I, Boisclair J, Dubey J, Kennedy S, Martineau D (2000) Toxoplasmosis in beluga whales (Delphinapterus leucas) from the St Lawrence estuary: two case reports and a serological survey. J Comp Pathol 122(1):73-76. https://doi.org/10.1053/jcpa.1999. 0341

2. Bossart GD (2006) Marine mammals as sentinel species for oceans and human health. Oceanography 19(2):134-137. https:// doi.org/10.1177/0300985810388525

3. Aguirre AA, Longcore T, Barbieri M, Dabritz H, Hill D, Klein PN et al (2019) The one health approach to toxoplasmosis: epidemiology, control, and prevention strategies. Eco Health 16(2):378-390. https://doi.org/10.1007/s10393-019-01405-7

4. Dubey J (2004) Toxoplasmosis-a waterborne zoonosis. Vet Parasitol 126(1-2):57-72. https://doi.org/10.1016/j.vetpar.2004. 09.005

5. Hoseini SA, DehganiN SM, Daryani A, Gholami S, Ebrahimi F, Pagheh AS, Arefkhah N (2014) Serological survey of toxoplasmosis in pregnant women. J Maz Univ Med Sci 24(114):146-150

6. Safarpour H, Cevik M, Zarean M, Barac A, Hatam-Nahavandi K, Rahimi MT et al (2020) Global status of Toxoplasma gondii infection and associated risk factors in people living with HIV. AIDS 34(3):469-474. https://doi.org/10.1097/QAD.0000000000002424

7. Anvari D, Sharif M, Sarvi S, Aghayan SA, Gholami S, Pagheh AS, Hosseini SA, Saberi R et al (2019) Seroprevalence of Toxoplasma gondii infection in cancer patients: a systematic review and meta-analysis. Microb Pathog 129:30-42. https://doi.org/10. 1016/j.micpath.2019.01.040

8. Djurkovic-Djakovic O, Dupouy-Camet J, Van der Giessen J, Dubey JP (2019) Toxoplasmosis: overview from a one health perspective. Food Waterborne Parasitol 15:e00054. https://doi. org/10.1016/j.fawpar.2019.e00054

9. Fujii K, Kakumoto C, Kobayashi M, Saito S, Kariya T, Watanabe Y et al (2007) Seroepidemiology of Toxoplasma gondii and Neospora caninum in seals around Hokkaido, Japan. J Vet Med Sci 69(4):393-398. https://doi.org/10.1292/jvms.69.393

10. Fayer R, Dubey JP, Lindsay DS (2004) Zoonotic protozoa: from land to sea. Trends Parasitol 20(11):531-536. https://doi.org/10. 1016/j.pt.2004.08.008

11. Lindsay DS, Collins MV, Mitchell SM, Cole RA, Flick GJ, Wetch $\mathrm{CN}$ et al (2003) Sporulation and survival of Toxoplasma gondii oocysts in seawater. J Eukaryot Microbiol 50:687-688. https://doi. org/10.1111/j.1550-7408.2003.tb00688.x

12. Lindsay DS, Dubey J (2009) Long-term survival of Toxoplasma gondii sporulated oocysts in seawater. J Parasitol 95(4):10191020. https://doi.org/10.1645/GE-1919.1

13. Cole RA, Lindsay D, Howe D, Roderick CL, Dubey J, Thomas N et al (2000) Biological and molecular characterizations of Toxoplasma gondii strains obtained from southern sea otters (Enhydra 
lutris nereis). J Parasitol 86(3):526-530. https://doi.org/10.1645/ 0022-3395(2000)086[0526:BAMCOT]2.0.CO;2

14. Ubey JP, Murata FH, Cerqueira-Cézar CK, Kwok OC, Grigg ME (2020) Recent epidemiologic and clinical importance of Toxoplasma gondii infections in marine mammals: 2009-2020. Vet Parasitol. https://doi.org/10.1016/j.vetpar.2020.109296

15. Mathews PD, Da Silva VM, Rosas FC, Neto JAdA, Lazzarini SM, Ribeiro DC et al (2012) Occurrence of antibodies to Toxoplasma gondii and Lepstospira spp. in manatees (Trichechus inunguis) of the Brazilian Amazon. J Zoo Wildl Med 43(1):85-88. https://doi. org/10.1638/2011-0178.1

16. Oksanen A, Asbakk K, Prestrud K, Aars J, Derocher A, Tryland M et al (2009) Prevalence of antibodies against Toxoplasma gondii in polar bears (Ursus maritimus) from Svalbard and East Greenland. J Parasitol 95(1):89-94. https://doi.org/10.1645/GE-1590.1

17. Dubey J, Zarnke R, Thomas N, Wong S, Van Bonn W, Briggs M et al (2003) Toxoplasma gondii, Neospora caninum, Sarcocystis neurona, and Sarcocystis canis-like infections in marine mammals. Vet Parasitol 116(4):275-296. https://doi.org/10.1016/ s0304-4017(03)00263-2

18. Dubey J, Mergl J, Gehring E, Sundar N, Velmurugan G, Kwok O et al (2009) Toxoplasmosis in captive dolphins (Tursiops truncatus) and walrus (Odobenus rosmarus). J Parasitol 95(1):82-85. https://doi.org/10.1645/GE-1764.1

19. Miller M, Conrad P, James E, Packham A, Toy-Choutka S, Murray MJ et al (2008) Transplacental toxoplasmosis in a wild southern sea otter (Enhydra lutris nereis). Vet Parasitol 153(1-2):12-18. https://doi.org/10.1016/j.vetpar.2008.01.015

20. Kreuder C, Miller M, Jessup D, Lowenstine LJ, Harris M, Ames J et al (2003) Patterns of mortality in southern sea otters (Enhydra lutris nereis) from 1998-2001. J Wildl Dis 39(3):495-509. https:// doi.org/10.7589/0090-3558-39.3.495

21. Thomas N, Dubey J, Lindsay D, Cole RA, Meteyer C (2007) Protozoal meningoencephalitis in sea otters (Enhydra lutris): a histopathological and immunohistochemical study of naturally occurring cases. J Comp Pathol 137(2-3):102-121. https://doi. org/10.1016/j.jcpa.2007.05.001

22. Miller MA, Sverlow K, Crosbie PR, Barr BC, Lowenstine LJ, Gulland FM et al (2001) Isolation and characterization of two parasitic protozoa from a Pacific harbor seal (Phoca vitulina richardsi) with mening oencephalomyelitis. J Parasitol 87(4):816822. https://doi.org/10.1645/0022-3395(2001)087[0816:IACOTP] 2.0.CO;2

23. Pelt RV, Dieterich R (1973) Staphylococcal infection and toxoplasmosis in a young harbor seal. J Wildl Dis 9(3):258-261. https://doi.org/10.7589/0090-3558-9.3.258

24. Van Wormer E, Fritz H, Shapiro K, Mazet JAK, Conrad PA (2013) Molecules to modeling: Toxoplasma gondii oocysts at the humananimal-environment interface. Comp Immunol Microbiol Infect Dis 36(3):217-231. https://doi.org/10.1016/j.cimid.2012.10.006

25. Mazzariol S, Marcer F, Mignone W, Serracca L, Goria M, Marsili L et al (2012) Dolphin Morbillivirus and Toxoplasma gondii coinfection in a Mediterranean fin whale (Balaenoptera physalus). BMC Vet Res 8(1):1-5. https://doi.org/10.1186/1746-6148-8-20

26. van de Velde N, Devleesschauwer B, Leopold M, Begeman L, Ijsseldijk L, Hiemstra S et al (2016) Toxoplasma gondii in stranded marine mammals from the North Sea and Eastern Atlantic Ocean: findings and diagnostic difficulties. Vet Parasitol 230:25-32. https://doi.org/10.1016/j.vetpar.2016.10.021

27. Conrad PA, Miller M, Kreuder C, James E, Mazet J, Dabritz H et al (2005) Transmission of Toxoplasma: clues from the study of sea otters as sentinels of Toxoplasma gondii flow into the marine environment. Int J Parasitol 35(11-12):1155-1168. https://doi.org/ 10.1016/j.ijpara.2005.07.002

28. Jessup DA, Miller M, Ames J, Harris M, Kreuder C, Conrad PA et al (2004) Southern sea otter as a sentinel of marine ecosystem health. EcoHealth 1(3):239-245. https://doi.org/10.1007/ s10393-004-0093-7

29. Stewart JR, Gast RJ, Fujioka RS, Solo-Gabriele HM, Meschke JS, Amaral-Zettler LA et al (2008) The coastal environment and human health: microbial indicators, pathogens, sentinels and reservoirs. J Environ Health 7(2):1-14. https://doi.org/10.1186/ 1476-069X-7-S2-S3

30. Moher D, Liberati A, Tetzlaff J, Altman DG (2010) Preferred reporting items for systematic reviews and meta-analyses: the PRISMA statement. Int J Surg 8(5):336-341. https://doi.org/10. 1016/j.ijsu.2010.02.007

31. Moosazadeh M, Nekoei-Moghadam M, Emrani Z, Amiresmaili M (2014) Prevalence of unwanted pregnancy in Iran: a systematic review and meta-analysis. Int J health Plan Manag 29(3):e277e290. https://doi.org/10.1002/hpm.2184

32. Von Elm E, Altman DG, Egger M, Pocock SJ, Gøtzsche PC, Vandenbroucke JP (2007) The Strengthening the Reporting of Observational Studies in Epidemiology (STROBE) statement: guidelines for reporting observational studies. Bull World Health Organ 85:867-872. https://doi.org/10.1016/j.ijsu.2014.07.013

33. Miller M, Gardner I, Kreuder C, Paradies D, Worcester K, Jessup D et al (2002) Coastal freshwater runoff is a risk factor for Toxoplasma gondii infection of southern sea otters (Enhydra lutris nereis). Int J Parasitol 32(8):997-1006. https://doi.org/10.1016/ s0020-7519(02)00069-3

34. Johnson CK, Tinker MT, Estes JA, Conrad PA, Staedler M, Miller MA et al (2009) Prey choice and habitat use drive sea otter pathogen exposure in a resource-limited coastal system. Proc Natl Acad Sci 106(7):2242-2247. https://doi.org/10.1073/pnas.0806449106

35. Shapiro K, Miller M, Mazet J (2012) Temporal association between land-based runoff events and California sea otter (Enhydra lutris nereis) protozoal mortalities. J Wildl Dis 48(2):394404. https://doi.org/10.7589/0090-3558-48.2.394

36. Packham AE, Sverlow KW, Conrad PA, Loomis EF, Rowe JD, Anderson ML et al (1998) A modified agglutination test for Neospora caninum: development, optimization, and comparison to the indirect fluorescent-antibody test and enzyme-linked immunosorbent assay. Clin Diagn Lab Immunol 5(4):467-473. https:// doi.org/10.1128/CDLI.5.4.467-473.1998

37. Aksoy U, Marangi M, Papini R, Ozkoc S, Delibas SB, Giangaspero A (2014) Detection of Toxoplasma gondii and Cyclospora cayetanensis in Mytilus galloprovincialis from Izmir Province coast (Turkey) by real time PCR/high-resolution melting analysis (HRM). Food Microbiol 44:128-135. https://doi.org/10.1016/j. fm.2014.05.012

38. Arkush KD, Miller MA, Leutenegger CM, Gardner IA, Packham AE, Heckeroth AR et al (2003) Molecular and bioassay-based detection of Toxoplasma gondii oocyst uptake by mussels (Mytilus galloprovincialis). Int J Parasitol 33(10):1087-1097. https://doi. org/10.1016/s0020-7519(03)00181-4

39. Shapiro K, Bahia-Oliveira L, Dixon B, Dumètre A, de Wit LA, VanWormer E et al (2019) Environmental transmission of Toxoplasma gondii: oocysts in water, soil and food. Food Waterborne Parasitol 15:e00049. https://doi.org/10.1016/j.fawpar.2019.e00049

40. Dubey J, Jones J (2008) Toxoplasma gondii infection in humans and animals in the United States. Int J Parasitol 38(11):12571278. https://doi.org/10.1016/j.ijpara.2008.03.007

41. Hosseini S, Amouei A, Sharif M, Sarvi S, Galal L, Javidnia J et al (2019) Human toxoplasmosis: a systematic review for genetic diversity of Toxoplasma gondii in clinical samples. Epidemiol Infect 147:e36. https://doi.org/10.1017/S0950268818002947

42. Ahmadpour E, Sarvi S, Soteh MBH, Sharif M, Rahimi MT, Valadan R et al (2017) Enhancing immune responses to a DNA vaccine encoding Toxoplasma gondii GRA14 by calcium phosphate nanoparticles as an adjuvant. Immunol Lett 185:40-47. https:// doi.org/10.1016/j.imlet.2017.03.006 
43. Dardé M (2008) Toxoplasma gondii, "new" genotypes and virulence. Parasite 15(3):366-371. https://doi.org/10.1051/parasite/ 2008153366

44. Dubey J, Fair P, Sundar N, Velmurugan G, Kwok OCH, McFee W et al (2008) Isolation of Toxoplasma gondii from bottlenose dolphins (Tursiops truncatus). J Parasitol 94(4):821-823. https:// doi.org/10.1645/GE-1444.1

45. Hancock K, Thiele LA, Zajac AM, Elvinger F, Lindsay DS (2005) Prevalence of antibodies to Toxoplasma gondii in raccoons (Procyon lotor) from an urban area of Northern Virginia. J Parasitol 91(3):694-695. https://doi.org/10.1645/GE-443R

46. Miller M, Miller W, Conrad PA, James E, Melli A, Leutenegger C et al (2008) Type X Toxoplasma gondii in a wild mussel and terrestrial carnivores from coastal California: new linkages between terrestrial mammals, runoff and toxoplasmosis of sea otters. Int J Parasitol 38(11):1319-1328. https://doi.org/10.1016/j.ijpara.2008. 02.005

47. Bowater RO, Norton J, Johnson S, Hill B, Odonoghue P, Prior $\mathrm{H}$ (2003) Toxoplasmosis in Indo-Pacific humpbacked dolphins (Sousa chinensis), from Queensland. Aust Vet J 81(10):627-632. https://doi.org/10.1111/j.1751-0813.2003.tb12509.x

48. Cabezón O, Resendes A, Domingo M, Raga J, Agustí C, Alegre F et al (2004) Seroprevalence of Toxoplasma gondii antibodies in wild dolphins from the Spanish Mediterranean coast. J Parasitol 90(3):643-644. https://doi.org/10.1645/GE-257R

49. Omata Y, Hammond T, Itoh K, Murata K (2005) Antibodies against Toxoplasma gondii in the Pacific bottlenose dolphin (Tursiops aduncus) from the Solomon Islands. J Parasitol 91(4):965967. https://doi.org/10.1645/GE-3457RN.1

50. Alekseev AY, Rozanova E, Ustinova E, Tumanov YI, Kuvshinova I, Shestopalov A (2007) The prevalence of antibodies to morbilliviruses, Brucella, and Toxoplasma in the Black Sea bottlenose dolphin Tursiops truncatus ponticus maintained in captivity. Russ J Mar Biol 33(6):425-428

51. Alekseev AY, Reguzova AY, Rozanova E, Abramov A, Tumanov YV, Kuvshinova I et al (2009) Detection of specific antibodies to morbilliviruses, Brucella and Toxoplasma in the Black Sea dolphin Tursiops truncatus ponticus and the beluga whale Delphinapterus leucas from the Sea of Okhotsk in 2002-2007. Russ J Mar Biol 35(6):494-497. https://doi.org/10.1134/S106307400 9060078

52. Forman D, West N, Francis J, Guy E (2009) The sero-prevalence of Toxoplasma gondii in British marine mammals. Mem Inst Oswaldo Cruz 104(2):296-298. https://doi.org/10.1590/S007402762009000200024

53. Di Guardo G, Proietto U, Di Francesco CE, Marsilio F, Zaccaroni A, Scaravelli D et al (2010) Cerebral toxoplasmosis in striped dolphins (Stenella coeruleoalba) stranded along the Ligurian Sea coast of Italy. Vet Pathol 47(2):245-253. https://doi.org/10.1177/ 0300985809358036

54. Pretti C, Mancianti F, Nardoni S, Ariti G, Monni G, Bello Dd et al (2010) Detection of Toxoplasma gondii infection in dolphins stranded along the Tuscan coast, Italy. Rev Med Vet 161(10):428-431

55. Santos PS, Albuquerque GR, Da Silva V, Martin AR, Marvulo MFV, Souza S et al (2011) Seroprevalence of Toxoplasma gondii in free-living Amazon River dolphins (Inia geoffrensis) from central Amazon, Brazil. Vet Parasitol 183(1-2):171-173. https:// doi.org/10.1016/j.vetpar.2011.06.007

56. Alvarado-Esquivel C, Sánchez-Okrucky R, Dubey J (2012) Serological evidence of Toxoplasma gondii infection in captive marine mammals in Mexico. Vet Parasitol 184(2-4):321-324. https://doi. org/10.1016/j.vetpar.2011.08.036

57. Roe WD, Howe L, Baker EJ, Burrows L, Hunter SA (2013) An atypical genotype of Toxoplasma gondii as a cause of mortality in Hector's dolphins (Cephalorhynchus hectori). Vet Parasitol 192(1-3):67-74. https://doi.org/10.1016/j.vetpar.2012.11.001

58. Bernal-Guadarrama MJ, Salichs J, Almunia J, García-Parraga D, Fernández-Gallardo N, Santana-Morales MÁ et al (2014) Development of an indirect immunofluorescence technique for the diagnosis of toxoplasmosis in bottlenose dolphins. Parasitol Res 113(2):451-455. https://doi.org/10.1007/s00436-013-3674-y

59. Profeta F, Di Francesco CE, Marsilio F, Mignone W, Di Nocera F, De Carlo E et al (2015) Retrospective seroepidemiological investigations against Morbillivirus, Toxoplasma gondii and Brucella spp. in cetaceans stranded along the Italian coastline (1998-2014). Res Vet Sci 101:89-92. https://doi.org/10.1016/j.rvsc.2015.06.008

60. Pintore MD, Mignone W, Di Guardo G, Mazzariol S, Ballardini M, Florio CL et al (2018) Neuropathologic findings in cetaceans stranded in Italy (2002-14). J Wildl Dis 54(2):295-303. https:// doi.org/10.7589/2017-02-035

61. Costa-Silva S, Sacristán C, Gonzales-Viera O, Díaz-Delgado J, Sánchez-Sarmiento AM, Marigo J et al (2019) Toxoplasma gondii in cetaceans of Brazil: a histopathological and immunohistochemical survey. Rev Bras Parasitol Vet 28:395-402

62. Oksanen A, Tryland M, Johnsen K, Dubey J (1998) Serosurvey of Toxoplasma gondii in North Atlantic marine mammals by the use of agglutination test employing whole tachyzoites and dithiothreitol. Comp Immunol Microbiol Infect Dis 21(2):107-114. https://doi.org/10.1016/s0147-9571(97)00028-3

63. Hermosilla C, Silva LM, Kleinertz S, Prieto R, Silva MA, Taubert A (2016) Endoparasite survey of free-swimming baleen whales (Balaenoptera musculus, B. physalus, B. borealis) and sperm whales (Physeter macrocephalus) using non/minimally invasive methods. Parasitol Res 115(2):889-896. https://doi.org/10.1007/ s00436-015-4835-y

64. Alekseev AY, Shpak O, Adamenko L, Glazov D, Galkina I, Schelkanov MY et al (2017) Serological detection of causative agents of infectious and invasive diseases in the beluga whale Delphinapterus leucas (Pallas, 1776) (Cetacea: Monodontidae) from Sakhalinsky Bay. Russ J Mar Biol 43(6):485-490. https:// doi.org/10.1134/S1063074017060037

65. Iqbal A, Lair S, Dixon B (2018) Toxoplasma gondii infection in stranded St. Lawrence Estuary beluga Delphinapterus leucas in Quebec, Canada. Dis Aquat Org 130(3):165-175. https://doi.org/ 10.3354/dao03262

66. Marcer F, Marchiori E, Centelleghe C, Ajzenberg D, Gustinelli A, Meroni V et al (2019) Parasitological and pathological findings in fin whales Balaenoptera physalus stranded along Italian coastlines. Dis Aquat Organ 133(1):25-37. https://doi.org/10. 3354/dao03327

67. Lambourn D, Jeffries S, Dubey J (2001) Seroprevalence of Toxoplasma gondii in harbor seals (Phoca vitulina) in southern Puget Sound, Washington. J Parasitol 87(5):1196-1197. https:// doi.org/10.1645/0022-3395(2001)087[1196:SOTGIH]2.0.CO;2

68. Measures LN, Dubey J, Labelle P, Martineau D (2004) Seroprevalence of Toxoplasma gondii in Canadian pinnipeds. J Wildl Dis 40(2):294-300. https://doi.org/10.7589/0090-3558-40.2.294

69. Simon A, Chambellant M, Ward BJ, Simard M, Proulx J-F, Lévesque B et al (2011) Spatio-temporal variations and age effect on Toxoplasma gondii seroprevalence in seals from the Canadian Arctic. Parasitology 138(11):1362-1368. https://doi. org/10.1017/S0031182011001260

70. Rengifo-Herrera C, Ortega-Mora LM, Álvarez-García G, Gómez-Bautista M, García-Párraga D, García-Peña FJ et al (2012) Detection of Toxoplasma gondii antibodies in Antarctic pinnipeds. Vet Parasitol 190(1-2):259-262. https://doi.org/10. 1016/j.vetpar.2012.05.020

71. Jensen S, Nymo I, Forcada J, Godfroid J, Hall A (2012) Prevalence of Toxoplasma gondii antibodies in pinnipeds from Antarctica. Ecol Manag Restor 2:129-138 
72. Jankowski G, Adkesson MJ, Saliki JT, Cárdenas-Alayza S, Majluf P (2015) Survey for infectious disease in the South American fur seal (Arctocephalus australis) population at Punta San Juan, Peru. J Zoo Wildl Med 46:246-254. https://doi.org/ $10.1638 / 2014-0120.1$

73. Bauer KL, Goertz CE, Belovarac JA, Walton RW, Dunn JL, Tuomi P (2016) Infectious disease and toxicological monitoring of stranded pacific harbor seals (Phoca vitulina richardsi) in cook inlet as surrogates for monitoring endangered belugas (Delphinapterus leucas). J Zoo Wildl Med 47(3):770-780. https://doi.org/10.1638/2015-0147.1

74. Namroodi S, Shirazi AS, Khaleghi SR, Mills JN, Kheirabady V (2018) Frequency of exposure of endangered Caspian seals to canine distemper virus, Leptospira interrogans, and Toxoplasma gondii. PLoS ONE 13(4):e0196070. https://doi.org/10. 1371/journal.pone.0196070

75. Carlson-Bremer D, Colegrove KM, Gulland FM, Conrad PA, Mazet JA, Johnson CK (2015) Epidemiology and pathology of Toxoplasma gondii in free-ranging California sea lions (Zalophus californianus). J Wildl Dis 51(2):362-373. https://doi.org/ 10.7589/2014-08-205

76. Michael S, Howe L, Chilvers B, Morel P, Roe W (2016) Seroprevalence of Toxoplasma gondii in mainland and sub-Antarctic New Zealand sea lion (Phocarctos hookeri) populations. N Z Vet J 64(5):293-297. https://doi.org/10.1080/00480169.2016. 1191974

77. Tocidlowski ME, Lappin MR, Sumner PW, Stoskopf MK (1997) Serologic survey for toxoplasmosis in river otters. J Wildl Dis 33(3):649-652. https://doi.org/10.7589/0090-3558-33.3.649

78. Miller M, Gardner I, Packham A, Mazet J, Hanni K, Jessup D et al (2002) Evaluation of an indirect fluorescent antibody test (IFAT) for demonstration of antibodies to Toxoplasma gondii in the sea otter (Enhydra lutris). J Parasitol 88(3):594-599. https:// doi.org/10.1645/0022-3395(2002)088[0594:EOAIFA]2.0.CO;2

79. Miller MA, Grigg ME, Kreuder C, James E, Melli A, Crosbie $\mathrm{P}$ et al (2004) An unusual genotype of Toxoplasma gondii is common in California sea otters (Enhydra lutris nereis) and is a cause of mortality. Int J Parasitol 34(3):275-284. https://doi. org/10.1016/j.ijpara.2003.12.008

80. Gaydos JK, Conrad PA, Gilardi KV, Blundell GM, Ben-David M (2007) Does human proximity affect antibody prevalence in marine-foraging river otters (Lontra canadensis)? J Wildl Dis 43(1):116-123. https://doi.org/10.7589/0090-3558-43.1.116

81. Verma SK, Knowles S, Cerqueira-Cézar CK, Kwok OC, Jiang $\mathrm{T}, \mathrm{Su} \mathrm{C}$ et al (2018) An update on Toxoplasma gondii infections in northern sea otters (Enhydra lutris kenyoni) from Washington State, USA. Vet Parasitol 258(133):7. https://doi.org/10.1016/j. vetpar.2018.05.011

82. Esmerini PO, Gennari SM, Pena HF (2010) Analysis of marine bivalve shellfish from the fish market in Santos city, São Paulo state, Brazil, for Toxoplasma gondii. Vet Parasitol 170(1-2):8-13. https://doi.org/10.1016/j.vetpar.2010.01.036

83. Zhang M, Yang Z, Wang S, Tao L, Xu L, Yan R et al (2014) Detection of Toxoplasma gondii in shellfish and fish in parts of China. Vet Parasitol 200(1-2):85-89. https://doi.org/10.1016/j. vetpar.2013.10.022

84. Marangi M, Giangaspero A, Lacasella V, Lonigro A, Gasser RB (2015) Multiplex PCR for the detection and quantification of zoonotic taxa of Giardia, Cryptosporidium and Toxoplasma in wastewater and mussels. Mol Cell Probes 29(2):122-125. https:// doi.org/10.1016/j.mcp.2015.01.001

85. Marquis ND, Record NR, Robledo JAF (2015) Survey for protozoan parasites in Eastern oysters (Crassostrea virginica) from the Gulf of Maine using PCR-based assays. Parasitol Int 64(5):299302. https://doi.org/10.1016/j.parint.2015.04.001

86. Ribeiro L, Santos L, Brito P Jr, Maciel B, Da Silva A, Albuquerque $\mathrm{G}$ (2015) Detection of Toxoplasma gondii DNA in Brazilian oysters (Crassostrea rhizophorae). Genet Mol Res 14(2):46584665. https://doi.org/10.4238/2015.May.4.25

87. Cong W, Zhang N-Z, Hou J-L, Wang X-C, Ma J-G, Zhu X-Q et al (2017) First detection and genetic characterization of Toxoplasma gondii in market-sold oysters in China. Infect Genet Evol 54:276-278. https://doi.org/10.1016/j.meegid.2017.07.014

88. Coupe A, Howe L, Burrows E, Sine A, Pita A, Velathanthiri N et al (2018) First report of Toxoplasma gondii sporulated oocysts and Giardia duodenalis in commercial green-lipped mussels (Perna canaliculus) in New Zealand. Parasitol Res 117(5):14531463. https://doi.org/10.1007/s00436-018-5832-8

89. Cong W, Zhang N-Z, Yuan D-Q, Zou Y, Li S, Liang Z-L (2019) Detection and genetic characterization of Toxoplasma gondii in market-sold mussels (Mytilus edulis) in certain provinces of China. Microb Pathogen 136:103687. https://doi.org/10.1016/j. micpath.2019.103687

90. Marquis ND, Bishop TJ, Record NR, Countway PD, Fernández Robledo JA (2019) Molecular Epizootiology of Toxoplasma gondii and Cryptosporidium parvum in the Eastern Oyster (Crassostrea virginica) from Maine (USA). Pathogens 8(3):125. https:// doi.org/10.3390/pathogens8030125

91. Marino AMF, Giunta RP, Salvaggio A, Castello A, Alfonzetti T, Barbagallo A et al (2019) (2019) Toxoplasma gondii in edible fishes captured in the Mediterranean basin. Zoonoses Public Health 66(7):826-834. https://doi.org/10.1111/zph.12630

Publisher's Note Springer Nature remains neutral with regard to jurisdictional claims in published maps and institutional affiliations. 